This item was submitted to Loughborough's Research Repository by the author.

Items in Figshare are protected by copyright, with all rights reserved, unless otherwise indicated.

\title{
The social construction of the sociology of sport: a professional project
}

\section{PLEASE CITE THE PUBLISHED VERSION}

http://dx.doi.org/10.1177/1012690212452362

\section{PUBLISHER}

(c) SAGE Publications Ltd

\section{VERSION}

AM (Accepted Manuscript)

\section{PUBLISHER STATEMENT}

This work is made available according to the conditions of the Creative Commons Attribution-NonCommercialNoDerivatives 4.0 International (CC BY-NC-ND 4.0) licence. Full details of this licence are available at: https://creativecommons.org/licenses/by-nc-nd/4.0/

\section{LICENCE}

CC BY-NC-ND 4.0

\section{REPOSITORY RECORD}

Malcolm, Dominic. 2019. "The Social Construction of the Sociology of Sport: A Professional Project”. figshare. https://hdl.handle.net/2134/18867. 


\title{
The Social Construction of the Sociology of Sport: a Professional Project ${ }^{1}$
}

\begin{abstract}
This paper presents a historical sociological analysis of the sociology of sport. It draws on theoretical insights from the sociology of professions to examine 'state of the field' reviews written by sociologists of sport. The paper argues that in establishing why the sociology of sport emerged, how people identified its earliest manifestations, and how the subdiscipline's boundaries were drawn, the political dynamics and consequences of the social construction of the field become apparent. This social construction is conceived of as a 'professional project' through which a knowledge domain, and this group's authoritative status, was established. Sociologists of sport sought to validate their professional project through appeals to the sociological 'mainstream' and the correlative distancing from physical education. These reviews consistently obscure this professional project and portray a lineage which is logical, inevitable and consensual.
\end{abstract}

With some predicting the sociology of sport’s 'impending demise' (Atkinson 2011: 136) stemming from ‘a debilitating blend of introspective and ineffectual parochialism’ (Silk and Andrews, 2011: 5), the International Sociology of Sport Association's (ISSA) forthcoming $50^{\text {th }}$ anniversary presents an opportune moment to reflect on the area with which most readers of this journal self-identify. Such stocktaking is far from unusual in the sociology of sport. Indeed a quarter of a century ago Jay Coakley (1987: 63) remarked on the 'impressive' number of 'state of the field' papers. But in recent years reviews of the area have become less frequent. In their editorial to a subsequent special issue of the Sociology of Sport Journal John Loy and George Sage lamented the academic community’s response to 
their call for papers. It therefore remains the case that, 'given the maturation of sport sociology, both nationally and internationally ... a sociology of the sociology of sport now seems appropriate’ (Loy and Sage, 1997: 315).

These state of the field or stocktaking reviews are a useful resource in mapping the development of the sociology of sport. Often authored by people who were centrally involved in such processes, they document many of the key phases and developments in the subdiscipline. Yet there is a tendency for these accounts to essentially be 'self descriptions' of the field (Coakley, 1987: 63). Ingham and Donnelly (1997), for instance, chart the development of North American sociology of sport in terms of the dominant theoretical approaches at particular points in time, with the initial and largely functionalist paradigm first being replaced by a Millsian-informed Marxist approach, before itself being superseded by a variant of Gramscian cultural studies. Coakley and Dunning (2000) and Dunning (2004) similarly chart theoretical developments, identifying the principal epistemological and ontological divisions and concluding with some 'concerns' about the field's future development. As a consequence paradigmatic and methodological conflicts are frequently presented as the central dynamic of change.

But these accounts are also sociologically interesting in and of themselves. The large number of reviews which initially emerged, and their subsequent decline, reflects phases of insecurity and establishment as a subdiscipline. The predominance of accounts written by North American sociologists of sport (Coakley, 1987) suggests cultural and geographic specificities to these developmental processes. But perhaps most significantly these commentaries are not simply culturally neutral, 'factual', recordings of history, but also 'political' texts. In the sense that they are necessarily selective they reveal particular interests, biases and motives. Some are prescriptive as well as descriptive. Inconsistencies between accounts illustrate how different people have interpreted the 'history' of the sociology of 
sport in different ways. Comparison reveals what could have been as well as what became. In short, a review of these stocktaking accounts provides the basis of an examination of how the sociology of sport was socially constructed.

\section{The Sociology of Sport as a 'Profession'}

The theoretical premises of what is essentially a historical sociology of the sociology of sport derive from the sociology of professions. Professions can be defined as occupations 'based on advanced, or complex, or esoteric, or arcane knowledge’ (MacDonald, 1995: 1). Professions are typically identified as providing the authoritative and definitive voice over a particular area or practice (Freidson, 1970). They frequently have an ethical code and profess a service orientation through mediums such as mission statements.

While sociologists of sport may consider themselves part of the (university) teaching/research profession, or as members of 'other' disciplines (sociology, sports science), it is also the case that they constitute a (relatively) clearly defined occupational group which exhibits many of the 'traits' frequently associated with professions. For instance, included in the 'General Information' published on the ISSA website is reference to the 'complex' nature of its subject matter, the 'considerable knowledge' held within the subdiscipline, and the ability of members to provide 'expert advice' (emphasis added). A section on 'Relationship to Practice' identifies the service ISSA members provide in advising governments and others about the 'better use of human and environmental resources and thus ensuring that there is a sporting future for generations to come', and as advocates for athletes and disadvantaged groups. $^{2}$

It may be more or less possible to empirically substantiate these statements, but most significantly they also constitute what Larson (1977) describes as a 'professional project'. For Larson, professions should not be seen as static entities which have achieved certain 
characteristics, but as groups of people who seek occupational and personal reward in the form of market control by the collective and social mobility for the individual. Professions typically operate social closure (Parkin, 1974) to exclude 'undesirable' members and use a range of resources (e.g. ideological appeals to technical competence, expertise, service orientation, etc.) to convince others to accept their monopolistic claims. This is not to say that members of the profession do not also act altruistically - the hippocratic oath is not simply an ideological shroud for the medical profession - but that such statements need to be seen in a broader context.

Abbott's (1988) notion of a 'system of professions' provides a useful addition to Larson's work. While professions are based on the control and application of knowledge, their existence necessarily entails inter-professional relations with rival and contiguous groups. Professions therefore 'make up an interacting system' (Abbott, 1988: 33) of jurisdictional claims. The boundary maintenance that professions perform when they defend potential incursions into their respective jurisdictions, claims Abbott (1988: 2), constitute ‘the[ir] determining history'. Professions evolve as a result of their inter-relations with other professions.

Drawing on these ideas, this article attempts to delineate the dominant 'professional project' within the sociology of sport. It does so by analyzing the many state of the field reviews (plus information posted on the ISSA website) which sociologists of sport have produced, and illustrates how, through these ideological battles, the shape of the discipline is laid bare; how the resolution of these debates led to a particular subdisciplinary formation. Specifically, in establishing why the sociology of sport emerged, how people identified its earliest manifestations, and how the subdiscipline's boundaries were drawn, a professional project emerges whereby certain people could claim to be both authoritative and definitive over a particular area of study and, in so doing, marginalized competing claims. 


\section{Why did the Sociology of Sport Emerge?}

As Sage notes, 'the development of the sociology of sport has been a joint venture for physical educators and sociologists' (Sage, 1997: 325). Sociology had been fundamental to the 'New Physical Education' which developed in the US from around 1910, but pressure ‘to demonstrate a basic academic body of knowledge’ (Sage, 1997: 324) transformed physical education into ‘a loose coalition of subdisciplines' (Gruneau, 1976: 27). Led by Franklin Henry’s (1964) seminal paper 'Physical Education: An Academic Discipline’, the sociology of sport emerged alongside biomechanics, exercise physiology, sports psychology etc. as discipline-defined approaches to sport. The proliferation of subdisciplines was a 'symptom of sport's rationalization' (Gruneau, 1976: 28). The 'publish or perish’ ethos which ensued (Ingham and Donnelly, 1997: 363) meant that the revamped physical education field provided much of the emerging sociology of sport literature. Sage also identifies the increasing prominence of sport in North American culture, and some 'serious scholarly studies about sport’ such as sociologist James Coleman's The Adolescent Society (1961), but while there were distinct differences between the sociology of sport in North America and Europe at this time - 'nearly all' of the 30 plus US 'sport in society' courses in 1969 were in physical education departments whereas European courses were evenly divided between sociology and physical education department (Loy and Kenyon, 1969: 7-8) - on both sides of the Atlantic the subdiscipline was largely shaped by these two pre-existing disciplines.

Despite this, the reasons most frequently cited for the emergence of the sociology of sport tend to be couched in terms of a 'logical' corrective to the traditional neglect of sport in sociology and/or a consequence of sport's enhanced social significance. For instance, Sage (1980) argues that sport rarely featured in the 'mainstream' of the social sciences because it was perceived as a 'lower form of culture' and thus not worthy of serious study, as 'frivolous 
and ephemeral' and thus not easily addressed by social scientific theories. Moreover, the study of sport had offered few opportunities for academic prestige, there had been limited publishing outlets for sport-related research, and the poor quality of existing literature had retarded study. Snyder and Spreitzer (1974/80) similarly point to an element of 'snobbery' within sociology, and the belief that sports are not part of the 'real' world. Citing Dunning (1967), they go on to suggest that these views may stem from the (North American) commitment to the Protestant work ethic and to sociology's traditional orientation towards the social rather than the physical. While there are elements of overlap and teleology in the explanations given (many of these could equally be said to be consequences of the neglect of sport within the social sciences), a frequent argument has been that traditionally sport has not been perceived as a theoretically fertile or empirically significant field of enquiry.

Various broader social processes are also identified as contributing to the emergence of the sociology of sport. Sage (1997) refers to the increasing prominence of sport in American culture, a trend which Snyder and Spreitzer (1974/1980) attribute to post-war affluence. Coakley (1987) also points to the growing social prominence of sport but allies this with the development of journalistic investigations of social institutions (e.g. Watergate). Sport was similarly subject to increased media scrutiny and Coakley notes that over two dozen book length exposés about sport were published between 1969 and 1978. Sport, moreover, overlapped with key social and political issues: race-related civil rights; gender equity; pacifism and post-Vietnam concerns about violence; the relative merits of competition and cooperation, the distribution of social power and authority, and the role of higher education in society. Coakley (1978: 67) thus argues that the sociology of sport emerged, 'at least partially as a response to the awareness of problems generated by muckrakers, and to the call for changes by reformers'. 
Dunning’s (2004) ‘European’ perspective on the emergence of the sociology of sport identifies five mutually supporting processes. Like Coakley and Snyder and Sprietzer, Dunning cites wider social changes, and the increasing use of sport for political ends during the Cold War in particular. But in contrast to the other accounts, Dunning puts greater emphasis on developments within academia. These include: 1) the recognition by physical educators that sports are culturally and historically relative social practices; 2) the recognition by some sociologists (he cites Theordor Adorno, Norbert Elias, Charles Page and Gregory Stone) that the investigation of sport would enhance sociology per se; 3) the expansion of universities and the increased competition within and between disciplines; and 4) the 'permissive revolution' which, grounded in the relative empowerment of subordinate groups (females, minority ethnic groups, the working classes and youth) and fuelling left-oriented and radical ways of thinking, boosted the popularity of (a critical) sociology. ${ }^{3}$ It could also be argued that the field was driven by intellectual motivations, by people who felt that their scholarship could make a significant and positive impact on the social world (e.g. Harry Edwards) and who were bonded together by a shared sense of being pioneers expanding the boundaries of sociology.

There is supporting empirical evidence for the claims in each of these accounts but, most significantly, by identifying 'external' causes sociologists of sport effectively obfuscate the professional project of which they were a part. For instance, in locating the emerging subdiscipline within the inadequacies of 'mainstream' sociology while being entirely uncritical of physical education, these accounts locate the subdiscipline as an extension of the former and relatively distinct from the latter. As subsequent sections demonstrate, key actors perceived that social mobility would be enhanced by their close association with sociology rather than physical education. Further, by effectively portraying the emergence of the sociology of sport as a predominantly macro-social process, the less palatable (perhaps 
unintentional) aspects of a professional project - social closure and knowledge monopoly claims - were obscured. Indeed, while citing broader social changes and the inadequacies of existing sociological approaches, these accounts depict the subdiscipline's emergence as inevitable and/or logical - academics responding to social 'needs' or existing shortcomings. Of course, in part they were but the reality was that individuals also had much to gain from these developments. As McPherson (1975) argues, the first generation of sociologists of sport developed their interest in the area some point after their formal education ended. Members of this group were trained in sociology and interested in sport, or trained as physical educators and interested in social phenomena. These were, therefore, 'marginal men, neither sociologists nor physical educators', whose early careers were 'characterized by role conflict as they sought to legitimate both the introduction of new courses and the type of research they were undertaking' (McPherson, 1975: 57). These individuals were therefore neither neutral nor ambivalent to these processes. As we will see in the next section they were active agents of change. As we will see in the concluding section, they did not always act in unison.

\section{What Constituted the Emergence of the Sociology of Sport?}

The mid-1960s marked the beginning of a phase of rapid change as people - drawn from either sociology or physical education - began to call for, identify, and establish an institutional presence for the sociology of sport (see, e.g., Kenyon and Loy, 1965/69; Daniels, 1966/69; Erbach, 1966/69; Dunning, 1967). In so doing they defined two developments as central: the emergence of a body of literature, and an organizational structure, for the sociology of sport. Though on the one hand apolitical acts, each also bears the hallmarks of a professional project. Identifying literature helped delineate the empirical and methodological boundaries of the emerging profession and thus the scope of expertise and authority but it also constituted part of the legitimacy claims of individuals. Identifying 
specific meetings involving particular people served as a medium to champion the contributions of those who would subsequently achieve social mobility and establish a dominant position within the field, while obscuring the influence of certain 'undesirable' members.

\section{Literary Emergence}

Goudsblom (1977: 18) notes that 'it is customary to write the history of sociology in terms of individual contributors'. He further contends that this approach is ultimately flawed, for 'no matter which name is chosen there is something arbitrary and misleading about the choice'. The difference between the texts which are included/excluded is often just a matter of degree. Many of those who have reviewed the development of the sociology of sport recognize this. For example, Sage (1980: 11) notes that 'it is always difficult, as well as risky' to identify a specific incident or text. But despite such awareness the selection of literature in sociology of sport reviews is far from arbitrary. Indeed it exhibits a distinct pattern, invariably highlighting three types of literature: 1) 'classical' sociological texts which address sport as part of a broader analysis; 2) texts which are either defined as addressing sport 'un-sociologically' or which address sport-related activities rather than sport per se; and 3) miscellaneous texts which are both sport-focused and sociologically-orientated. What do these literature selections reveal about the professional project of sociologists of sport?

Loy and Kenyon (1969) were amongst the first to identify the discussion of sport by ‘mainstream’ sociologists. They note that Georg Simmel (1917), Max Weber (1904), Erving Goffman (1961), Thorsten Veblen (1899) and William Graham Sumner (1906) had discussed the 'function' of games in society. Lüschen (1980: 315) similarly cites Weber and Simmel plus the work of Herbert Spencer (1861). Gruneau (1976: 12) cites Veblen, George Herbert Mead (1934) and Weber, while Coakley and Dunning (2000) cite Veblen, Weber and Sumner. 
Just as consistently, however, such reviews categorize these works as alterior to the subdiscipline. Lüschen (1980: 316) describes them as 'acknowledgements', limited by their inability to go beyond 'the commonsense meaning of sport'. Coakley and Dunning (2000: xxii) describe them as ‘proto-sociological’ studies of sport.

The second category of texts includes analyses of sport-related activities. Typically cited are works about 'play’ such as those of cultural historian Johan Huizinga (1938/1949), anthropologist John Roberts and psychologist Robert Sutton-Smith (Roberts et al., 1959; Roberts and Sutton-Smith, 1962; Sutton-Smith et al., 1963), and French anthropologist/philosopher/sociologist Roger Caillois (1961). Joffre Dumazedier’s (1966) work on the sociology of leisure is also sometimes cited in this regard (Kenyon and Loy, 1965; Loy and Kenyon, 1969). Studies such as Cozens and Stumpf's Sport in American Life (1953), McIntosh’s Sport in Society (1960), Natan’s Sport and Society (1958) and Morton’s Soviet Sport (1963) form an additional cohort of frequently referenced texts. Coakley and Dunning (2000) go back further, citing Beckford's Thoughts on Hare and Foxhunting (1796), Egan's Boxiana (1812) and Shearman's (1887; 1889) studies of the development of football, rugby and athletics. Finally a number of non-English language works also tend to be included. Prominent amongst these are Steinitzer's Sport und Kultur (1910), Risse's Soziologie des Sports (1921), and Magnane’s Sociologie du Sport (1964).

Again all the texts within this category are dismissed as failing to produce a bona fide sociology of sport. While those addressing play or leisure are deemed insufficiently sportsoriented, the others are deemed insufficiently sociological. Sage (1980: 12), for instance, described McIntosh and Natan's work as 'basically descriptive accounts of the social dimensions of sport'. Wohl (1966: 5) similarly argues that Steinitzer and Risse's texts were 'the outcome of generally accepted opinion and prejudices about sports’. Lüschen (1980: 316) notes that these texts had 'hardly begun to address' a range of sociologically important issues. 
The final category of literature frequently cited includes Riesman and Denney’s (1951) study of the cultural diffusion of football, Weinberg and Arond's (1952) analysis of boxing subculture, Stone’s ‘American Sports: Play and Dis-play’ (1955), Helanko’s 'Sport and Socialization' (1957), and Grusky’s (1963) work on managerial succession and organizational effectiveness in baseball. Each article had an explicit sport focus and none could credibly be dismissed as unsociological due to publication in 'mainstream' sociology journals. Yet with the exception of Stone's work, each is accredited as a forerunner to, rather than signalling the start of, the sociology of sport. Specifically, all are defined as liminal because they did not form part of a sustained sociological analysis of sport.

Thus while the selection of key texts may be subjective, these subjective choices are structured by contextual concerns. For instance, citation of the first two literature categories can be seen to have intended and unintended consequences for the professional project of sociologists of sport. The main, intended, consequence was the attempt to establish the legitimacy of the sociological study of sport in a particular way. The selection gave greater emphasis to the roots of the subdiscipline in sociology. A potentially unintended consequence was to obscure the physical education lineage of the sociology of sport through the nonrecognition of texts from this field. The treatment of Ernst Jokl who wrote Medical Sociology and Cultural Anthropology of Sports and Physical Education (Jokl, 1964), and with Ernst Simon co-edited International Research in Sport and Physical Education (Jokl and Simon, 1964) is a case in point. The former was the first English language text to combine the words sociology and sport in its title. The latter included two chapters titled 'sociological' analyses of sport (by Leemans (1964) and Vlot (1964)) plus chapters from Max Horkheimer (1964) and the aforementioned Dumazedier (1964). Jokl was a prominent mover in the establishment of the International Council of Sport and Physical Education (ICSPE) from which, as we will 
see, ISSA's organizational structure emerged. ${ }^{4}$ Dumazedier was a founding member of ISSA's precursor, the International Committee for Sociology of Sport (ICSS).

Similarly works with a political orientation were ignored. There is, for instance, no mention of Richard Thompson's Race and Sport (1964). Harry Edwards' (1969) The Revolt of the Black Athlete is also frequently omitted. However the most notable omission of all is CLR James’ Beyond a Boundary (1963), a text which many now see as seminal, but which was almost entirely ignored by those charting the literary emergence of the sociology of sport. The citation of literature thus foregrounds a particular Anglo-American (and white) conception of sociology.

Significantly however these citations also provided a vehicle for individuals to demonstrate their sociological credentials. Simmel, Weber, etc. are cited not because of the comparative relevance of their work but because they were the people with whom (some) sociologists of sport wanted to be seen to be associated. Non-sociological and nonexclusively sports-oriented outputs are cited not because they constituted a precursor to the field, but because sociologists of sport needed to establish their professional boundaries in order to define the domain over which their definitive voice could be claimed.

But perhaps the most revealing of all literature citations was the rejection of certain texts because they did not form part of a more sustained individual commitment to the field. Kenyon and Loy tellingly noted that, 'few have committed their career' to the study of sport and society (1965/1969: 5) and in the rejection of certain work on the basis of output quantity, we again see the demarcation of a disciplinary boundary characteristic of a professional project. The line, it seems, was drawn on the basis of identity and the particular identity entailed resolving to form a new and discrete subdiscipline. The emergence of this identity was in part contingent upon an individual's involvement in the organizational development of the subdiscipline. Stone was hardly prolific but many see his work as seminal. Tellingly he 
did attend some of the early meetings. Thus a knowledge monopoly was asserted and the authoritative nature of others' work was disputed on both intellectual and non-intellectual grounds.

\section{Organizational Emergence}

Charting the organizational manifestations of the emergence of the subdiscipline would appear once again to be a relatively objective way of illustrating the development of the sociology of sport. A comparison of different accounts, however, illustrates discrepancies about what happened when, and which events were significant. Disagreements focus on three key issues: how the ICSS emerged; its programme of events; and the key personnel. In charting these differences we can see variations in the roles attributed to different actors. The retrospective recognition of the acts of some, and the correlative neglect of those of others is partly a consequence of the necessarily selective process of recollection, but it also reflects the subdiscipline's professional project and thus the socially constructed nature of the sociology of sport.

While there are some discrepancies in the early accounts (compare for instance Loy and Kenyon, 1969; Wohl, 1969; Lüschen, 1980; Lüschen and Sage, 1981) it now seems generally accepted that the ICSS first met in Geneva in 1964 and was formally constituted a year later in Warsaw in 1965. Andrzej Wohl became the committee’s first chairman, and Günther Lüschen, its first General Secretary. However, disagreements arise over the stimulus for these meetings. For instance, Wohl (1969) argues that the ICSS was established at the initiative of ICSPE and at its 1965 meeting resolved to gain International Sociological Association (ISA) accreditation. Loy and Kenyon (1969: 6) largely concur with Wohl arguing that the ICSS was 'formed as an outgrowth' of ICSPE and subsequently became an affiliate of ISA. However later accounts give greater emphasis to sociological impetuses. 
Sage (1980: 12) for instance claims that the ICSS was founded 'as an affiliate of ICSPE and ISA'. Lüschen (1980: 316) similarly describes the ICSS as a response to initiatives 'within the International Sociological Association and the UNESCO-affiliated International Council of Sport'. Contained within these respective accounts of the organizational emergence of the sociology of sport we see a shift in the perception of the respective influences of physical education and sociology.

While there is consensus that Cologne in 1966 was the venue for the first international symposium (Loy and Kenyon, 1969; Lüschen, 1980; Sage, 1980; Coakley and Dunning, 2000), reviews again contain disagreements over what stemmed from this meeting. Wohl (1969) indicates that the committee subsequently initiated meetings at Illinois (1967), Vienna (1968) and Leicester (UK) (1968), and planned a meeting for Switzerland in 1969 (which did take place) and Russia in 1970 (which did not). Loy and Kenyon (1969: 7), however, cite Cologne as the venue for the ICSS's first 'biennial Congress' and, in line with this, Sage (1980: 12) argues that 'the second conference sponsored by this committee was held in 1968 in Vienna'. McPherson (1975: 57) also depicts symposia as biennial citing the third, fourth and fifth events as having taken place in Canada (1971), Romania (1973) and Finland (1975) (the Finland conference was moved to Heidelberg, Germany at late notice (Anon, 1976)). In contrast, Coakley and Dunning (2000: xxiii) state that ICSS symposia were annual, listing subsequent meetings in Illinois (1967), Leicester (1968) and Magglingen/Macolin (Switzerland) (1969). Loy and Kenyon (1969: 6) and Coakley (1987) refer to an ‘international workshop' hosted by the University of Illinois in 1967, but do not accredit the ICSS as the organizing body. Wohl (1969: 192) describes this as a 'methodological working seminar', jointly hosted by the departments of physical education and sociology, organized by 'members of the Committee of Sport Sociology: Prof. Gregory P. Stone and Prof. G. Lüschen'. The ISSA website provides its own historical overview of conferences which 
distinguishes between international symposia and international workshops and includes Olympic Scientific Congresses and World Congresses of Sociology (but tellingly no ICSPE or other physical education meetings). The point here is not to provide a definitive list (if such a thing were possible) but to underscore how, for the first ten years of its existence (at least), the ICSS was a somewhat ad hoc organization the activities of which are open to multiple interpretations. Affiliated individuals worked on a number of fronts, had different opinions about what was being organized under the committee's auspices, and in what capacity individuals were involved. In charting the subdiscipline's history, therefore, certain choices are made and these, I argue, reflect a particular professional project.

This professional project becomes particularly evident in the different interpretations of who were the key personnel involved in these early meetings. According to the ISSA website the formation of the ICSS involved eight individuals: Dumazedier, Günter Erbach, Kalevi Heinila, Lüschen, Peter Mcintosh, Alexander Nowikow, ${ }^{5}$ Wohl, and Ferenc Hepp (vice President of ICSPE) who were joined by Stone for the 1965 Warsaw meeting. Wohl (1969: 191) however argues that this initiative was 'headed' by Hepp and ICSPE General Secretary William Jones, that 'three programmatic documents' prepared by Dumazedier, Lüschen and Erbach and Wohl were discussed by the Geneva delegates, and that a committee composed of Dumazedier, Erbach, Heinila, Lüschen, Mcintosh, Novikov, Stone and Wohl was initially established. In 1965 in Warsaw an 'Executive Bureau’ was formed consisting of Wohl, Lüschen, Heinila, Erbach, Mcintosh, Kyuzo Takenoshita, Rolf Albonico and Ruiz Randol. Loy and Kenyon (1969) state that the (full) Committee of 1968 had ten members the Executive Bureau plus Dumazedier and Stone - while the IRSS editorial board of 19691972 consisted of these ten plus Novikov.

Subsequent accounts show different variations. Ingham and Donnelly (1997: 366) argue that, 'judged by their words and organizational deeds', the key players in this 
movement were Wohl, Lüschen, Erbach, Heinila and Stone (all committee members), Eric Dunning, Fred Gras, Gerald Kenyon, John Loy, and Robert Sutton-Smith (who were not). Coakley and Dunning (2000: xxiii) recognize the role of Lüschen, Wohl, Macintosh, Stone, Albonico and Heinila (all committee members), plus Dunning, Kenyon, Loy and SuttonSmith (identified by Ingham and Donnelly), but further argue that Michel Bouet, Elias, Barbara Knapp (notably the only female), John Phillips, Walter Schafer, and Takaaki Niwa were 'participants in these early meetings'. Thus of the eleven members of the IRSS editorial board 1969-72, four (Wohl, Lüschen, Heinila, and Stone) are cited by both Coakley and Dunning and Ingham and Donnelly, two (Albonico and Macintosh) are cited by Coakley and Dunning but not by Ingham and Donnelly, one (Erbach) is cited by Ingham and Donnelly but not by Coakley and Dunning, and four (Dumazedier, Novikov, Randol and Takenoshita) are omitted from all later accounts. Neither of the ICSPE officials (Hepp or Jones) are cited in later accounts, yet about a dozen others are.

Thus different accounts express different perceptions of the significance of different individuals. Such interpretations are likely to be influenced by an individual's geographical location, social relations and academic interest. These accounts are probably also influenced by individual orientations to the sociology of sport's professional project. It may be that reviewers tend to cite those people who shared their subdisciplinary vision and those meetings which conformed to their view of a 'legitimate' sociology of sport. In so doing, both strategies retrospectively construct the development of the sociology of sport in particular ways.

Subsequently the North American Association for the Sociology of Sport (NASSS) would come to rival the ICSS/ISSA in terms of global influence but at this point in time, the North American relationship between the ICSS was ambivalent. For instance, Kenyon and Loy's (1965/1969) early programmatic statement for the sociology of sport 
covers 'European interest' within a brief paragraph and makes no reference to the 1964 Geneva meeting. In part this is complicated by Lüschen's move from West German to the US and Stone's ill-health which in turn may explain why the status of some conferences held in North America is disputed. While North American scholars were quantitatively well-represented (indeed there are more (5) North American sociologists of sport cited in the above passages than any other nationality) Europeans dominated key administrative positions in ICSS. There were, moreover, parallel organizational developments in North America at this time: the sociology of sport session at the 1966 American Alliance for Health Physical Education and Recreation (AAHPER) conference; the formation of 'a committee on sport sociology' sponsored by physical education departments in the American mid-west by 1967 (Loy and Kenyon, 1969); the sessions at the 1968 American Sociological Association (ASA) and American Association for the Advancement of Science (AAAS) conferences; and a meeting at the University of Wisconsin in 1968 under the sponsorship of the Committee for Institutional Cooperation (CIC), subseqeuntly described as the 'first major sociology of sport conference in the United States’ (Lüschen, 1969; Coakley, 1987). It would, however, be another decade before NASSS was established at the second CIC conference in 1978 (Coakley, 1987).

What shaped the Emerging Sociology of Sport?

As part of their professional project, the pioneers of the sociology of sport had to establish a critical mass and an internal coherence, while at the same time seeking legitimacy through external validation. These were interacting and sometimes contradictory processes. The balance between critical mass and internal coherence was delicate; larger groups tend to be 
less unified. Moreover, in attempting to appeal to the intellectual biases of a broader (sociological) constituency, it was expedient to shape the subdiscipline in a style which reduced its mass through the exclusion of some potential members. There were three key tensions in the emerging field: 1) the scope of analysis (physical culture vs sport); 2) the method of analysis (advocacy vs evaluation); and 3) disciplinary purity (multidisciplinarity vs sociology). Though I would not wish to suggest that the 'battle lines' were always explicitly, coherently or strictly drawn, in each case, physical educators would have come from an environment where the former position had been the norm. In each case, however, the latter position won the day and came to structure the subdiscipline.

\section{Scope of Analysis}

One of the key means by which professions in general and sociologists in particular assert their expertise is through the use of 'scientific terminology, a taxonomy which enables us to classify social phenomena in a clear and coherent conceptual framework' (Goudsblom, 1977: 25). This 'taxonomizing propensity' is particularly 'characteristic of fields in formation' (Ingham and Donnelly, 1977: 367) and sociologists of sport followed this conventional path, developing the subdiscipline alongside attempts to clarify their object of study. But concomitant with this process was the negotiation of disciplinary and therefore professional boundaries. Defining 'sport' entailed a debate about who sociologists of sport were and thus who was not a sociologist of sport.

In their overviews of the field Snyder and Sprietzer (1974/1980), Lüschen and Sage (1981), and Ingham and Donnelly (1997) all cite something akin to 'definitional attempts' as among the main strands of literature in the emergent field. Loy (1968), Lüschen (1970) Edwards (1973) and Ingham and Loy (1973) are identified as amongst the key works. Defining sport may have enabled communication between those in the subdiscipline but it 
also enabled certain people and groups to establish a position of authority. Through definitional discussions, individuals sought to separate their work from commonsense understandings. Snyder and Spreitzer argued that sport as a concept is 'self-evident until one is asked to define it' (1974/1980: 17). Gruneau similarly argued that this work is important as 'most conventional definitions of sport are misleading' (1976: 12, emphasis added). Defining sport in this manner distanced the emerging field from the literary precursors (e.g. play and leisure) identified and dismissed elsewhere.

These definitional attempts ultimately led to a relatively narrow field of analysis; to sport defined, for example, as structured, goal-oriented, competitive forms of play (McPherson et al., 1989). Yet the use of a broader definition did have its advocates. Erbach (1966), for example, continually referred to 'the field of physical culture and sport' and Dumazedier (1966), a prominent figure in the subdiscipline's initial organizational maneuvers, published on the sociology of leisure. As we have seen Robert Sutton-Smith, also present at early ICSS meetings, produced research focussed on play. But the relatively narrow conception of sport which came to dominate the subdiscipline ultimately led the analytical focus away from physical activity, and thus distanced the sociology of sport from both physical education and the study of leisure. The definition which became ascendant aligned with the professional project of those who wanted to establish a relatively distinct field and thus marginalized those who held on to links to cognate areas. It may also explain why the contribution of someone like Dumazedier may not always have been fully described in subsequent accounts.

\section{Method of Analysis}

The construction of disciplinary boundaries and the exclusion of some potential members of the emerging 'profession' also went hand-in-hand in debates over the method of analysis that 
would predominate. The first debate centred upon the role of values. The tendency amongst physical educators was/had been 'to evangelize about the "social development" objective of games and sports' (Sage, 1997: 322). Erbach (1966: 24), for instance, argued that 'our present-day system of physical culture must be substantially perfected', and thus sought to define the emerging subdiscipline via the traditional legitimating ideology of physical education (as serving some broader social benefit e.g. enhanced health, character or social integration). In contrast to this, others professed the value-neutrality of the subdiscipline; 'the sport sociologist is neither a spreader of gospel nor an evangelist for exercise’ (Kenyon and Loy, 1965: 38. See also Daniels, 1966/69). Sage (1997: 326) comments that Kenyon 'emphatically situated the sociology of sport firmly within the positivistic perspective of science' because he saw the subdiscipline's legitimacy resting in 'the positivist, empiricalanalytical paradigm of the established sciences’.

The debate about analytical method invoked a related question: did the existing approach to the study of sport have unique characteristics? Though recognizing that it had connections with 'kindred or principal branches of science', Erbach (1966: 30) argued that it should be 'the science of sport' which defined the emerging subdiscipline. Lüschen (1980), argued the opposite. There was no general theory of sport and as the sociology of sport could not lay claim to any special theory or method, a sociology through sport, rather than an detached sociology of sport, was to be preferred. By the conclusion of this debate, the subdiscipline would become closely aligned to, and dominated by, 'the standard canon of social science research methods’ (Lüschen, 1980: 324).

The system of professions in which the sociology of sport emerged meant that the coexistence of epistemological positions was problematic. A strong vein of advocacy would have undermined the legitimacy of the subdiscipline in the eyes of contemporary sociologists. Consequently the 'value-free social science' of the emerging subdiscipline was explicitly 
contrasted with the 'physical activity is good' assumptions traditionally held by physical educators (Kenyon and Loy, 1965: 38). The authoritative and definitive status of the subdiscipline was enabled by distancing it from its physical education roots. However, the debate was also geographically contoured, being most explicit and enduring in North America. Andrew Yiannakis lamented the fact that an applied sociology of sport had been hindered in the 1960s and 1970s and argued that if sport sociologists are truly interested in the worth of their research, logic dictates that their findings be put to the test in the world of sport' (1989: 5). Countering this, Ingham and Donnelly expressed concern that seeking validation within the 'market place' might have important ramifications for the research agenda in the sociology of sport: 'which aspects of the human condition are to be selected for special consideration and ... who is establishing priorities?' (1990: 61). Subsequently the mission statement of ISSA would identify 'the formation of policy' as an organizational goal, whereas NASSS would be organized 'exclusively for educational purposes'. ${ }^{6}$ Yet intentionally or not, the initial attempt to establish the legitimacy of the subdiscipline effectively policed its subsequent membership, enabled the social mobility of some and thus formed a central aspect of the sociology of sport professional project.

\section{Disciplinary Breadth}

The tension between 'critical mass' and 'internal cohesion' was evident in early discussions and practices regarding the balance between who to include within, and exclude from, the field. Wohl (1969: 191) notes that the ICSS had an initial target of 'no more than 70 corresponding members', but that this target was reached by the end of 1966, with membership exceeding 100 in 1969. By 1980 Lüschen (1980: 319) would claim that the ICSS had 250 'full and corresponding members' of whom 82 were research active. These 
researchers held positions in sport science (38), sociology (29), anthropology (3), education (3), philosophy (3), psychology (2), English (1) and planning (1) (plus 3 unknown). ${ }^{7}$ Most (48) were in Europe, though twenty were in North America and a minority (14) in Asia/Australia. The limits initially placed on the number of 'corresponding members' may partly reflect the limited resources of the committee, but more probably a desire to assert an element of 'quality control'. The latter is underscored by the ICSS's early policy of vetting potential members, 'according to involvement in research and academic teaching' (Lüschen, 1980: 319). The desire to both establish a critical mass while exerting a degree of control over those who wished to define themselves as sociologists of sport parallels the treatment of texts discussed earlier. The numerical prominence of sports scientists relative to sociologists contrasts with subsequent portrayals of the disciplinarly orientations of the field. Each can be seen as the manifestation of a particular professional project.

A significant group at this time, and one which is now often overlooked, was (social) psychologists. In his early attempt to define the field, Erbach (1966: 31) describes the questions posed by sociologists and social psychologists of sport as 'closely interrelated'. Kenyon and Loy (1965: 37) similarly note that the two 'have much in common', and further suggest that students of the sociology of sport should have a broad knowledge base within the social sciences. Daniels (1966: 15) goes even further, advocating that sports sociology should be 'the accepted identifying label' for a 'field of study (which) must logically be the social sciences'. Consequently, in the subdiscipline’s early years any study involving a group was defined as the sociology of sport, regardless of whether the theoretical focus was psychological, social psychological or sociological (McPherson, 1975). All the early conferences were multidisciplinary (Lüschen, 1969; Sage, 1997). Moreover, when Snyder and Spreitzer presented an outline of research in the field in 1974, two of the five areas they highlighted ('small groups' and 'social-psychological aspects') would, with the passing of 
time, become more firmly situated within psychology. Lüschen and Sage’s (1981) overview, and Ingham and Donnelly’s (1997) more recent account, demonstrate a similar division, with one ('sport as a subsystem') of three themes, and two ('socialization' and 'group dynamics') of seven themes respectively, becoming topics which would ultimately be partly or wholly positioned outside the subdiscipline.

The multidisciplinarity which was a cornerstone of the earliest incarnations of the sociology of sport reflected the traditions of physical education rather than sociology (note that only two ICSS research active scholars worked in psychology departments). Yet as the field developed a sociological focus became more uniform. Ingham and Donnelly (1997) attribute the division to 'methodological origins', there being a chasm between the 'field study, field experiment, laboratory experiment' of sports psychology and the ethnographic study of sociologists (Ingham and Donnelly, 1997: 370). Sociologists of sport's engagement with the work of Marx and C. Wright Mills further fuelled the break with psychology. It could also be argued that more recent theoretical developments, and in particular the style of language employed by those drawing on cultural studies and post-structuralism which some find esoteric and obfuscating, has further narrowed the field and limited its accessibility for both psychologists and physical educators. Yet for Ingham and Donnelly (1997: 371) 'in the early days, it was issues that brought scholars together before subdisciplinary specializations set them apart’.

As with many aspects of these reviews, Ingham and Donnelly's argument seeks to explain social processes in asocial terms, as logical outcomes or the product of 'commonsense'. Rather the establishment of the International Society of Sports Psychology in 1965 seems significant and reveals that others within this 'system of professions' were also undergoing their own professional projects. The continued citation of psychological research in early 'state of the field' papers suggests a thwarted desire for inclusion rather than their 
active attempt to exclude psychology. Yet once again, the reluctance to give greater weight to the contributions of social psychologists in the early formation of the sociology of sport reflects a tendency to champion a particular professional project; one that emphasizes the influence of sociology relative to physical education.

\section{Conclusion}

It can therefore be argued that the sociology of sport has been socially constructed in line with a relatively coherent professional project. Stocktaking and state of the field reviews consistently project a lineage which is more strongly sociological and only weakly derived from physical education on intellectual and non-intellectual grounds. They assert the relative expertise of proponents of the subdiscipline and dispute the authoritative and definitive nature of competing analyses of sport and sport-related phenomena. The sociology of sport has been shaped by debates which positioned the field relative to other groups in the broader system of professions/academic fields and emphasized the degree to which developments at a particular point in time represented a distinct disjuncture from previous practice. In this process connections with some groups (i.e. 'mainstream' sociologists) have been emphasized for legitimation purposes, while the role of others (i.e. with physical education backgrounds) has been downplayed. The 'market control' that sociologists of sport have been able to wield has necessarily entailed social mobility for some. The social closure inherent in this process becomes obscured as: a) macro-social processes are identified as responsible for the subdiscipline's emergence; b) debates, e.g., over the definition of 'sport', are portrayed as neutral acts of scholarly clarification rather than fundamentally structuring the boundaries of a domain of knowledge (and thus subdisciplinary membership); and c) key events and the roles of particular individuals undergo post-hoc rationalization. There is, I would argue, no logical inevitability to there being a distinct and identifiable subdiscipline called the 
sociology of sport for given a different amalgam of advocates it could alternatively have been consumed, for example, within the sociology of leisure/leisure studies, a sociology of physical culture, or a more broadly social science 'sports studies'. The sociology of sport was, therefore, socially constructed, partly through the agency of individuals in the field, but also in a broader structural context over which such individuals could exert relatively little control.

This point is particularly evident when one considers the distinct sex bias of participants in this process. Females - both authors and participants - are strikingly absent from the discussion presented above. It would not be until the mid- to late-1970s when authors such as Ellen Gerber, Carole Oglesby, M. Ann Hall and Jennifer Hargreaves would begin to more tangibly shape the area. In contrast to the organizational emergence of the sociology of sport through the formation of ICSS, Susan Greendorfer was an influential figure in the formation of NASSS (Coakley, 1987). While it has been my aim to show how the social construction of the sociology of sport was a contested process it has not been possible to explore all the nuances and international variations entailed. Knowledge does not develop in a vacuum and the very different domestic situations in which founders of the discipline did their 'day job' surely influenced their orientations and motivations for developing the field. As noted above civil rights and gender equity may have been more prominent for North Americans while the Cold War was perhaps a greater influence on academics in Poland, East and West Germany, and Britain. The greater influence of national governments (in terms of funding) and international agencies (NB Paris-based UNESCO played a significant role in the establishment of both ISA and ICSPE) over academia in Europe was no doubt also significant. The more frequent publication of 'state of the field' reviews in North America perhaps indicates a more prolonged and difficult process of 
legitimizing the field. Yet international conferences and publications not only alerted participants to differences but also enabled the cross fertilization and exchange of ideas. It should not be overlooked that many became tightly bonded through a sense of being intellectual pioneers and/or a force for positive social change.

While this article has focussed on the developmental processes of subdisciplinary formation, it is by no means intended to undermine prior work towards subdisciplinary formation or that which has subsequently been described as 'one of the liveliest and most fruitful of the parent subject's subdisciplines' (Dunning, 2004: 17). I would echo Carrington’s (2010: 9-10) retort to Wacquant's disparaging remarks about the subdiscipline; 'if the sociology of sport is indeed [as Wacqaunt claims] a space of intellectual oblivion ... it appears to be in a relatively happy state of effervescent oblivion'. The professional project of sociologists of sport has not been pursued to the neglect of altruistic and ethical goals any more than medicine has assumed major social significance without doctors curing the ailments of their patients. Moreover, like all social processes, it would be inaccurate to identify definitive beginning and end points. Many of the debates discussed in this article are on-going, and indeed have recently become more explicit through, e.g., the advocacy for the growth of an identifiable 'physical cultural studies' (Atkinson, 2001; Silk and Andrews, 2011).

Rather, later 'generations' of sociologists of sport owe it to their predecessors to retain the critical sociological imagination which they did so much to facilitate. We would be wise to recognize these points as our field re-shapes and reforms during its second half century. No field, no profession, is either static or entirely unified. Phases of more rapid and slower change will occur. Crucially however, developments are not merely intellectual, but also relate to the professional projects of individuals and the groups that they form. It would be unbefitting for such a vibrant area not to have a critical historical sociological analysis of its 
development and if we can use such knowledge to help shape the field's future development then so much the better.

\section{Notes}

\footnotetext{
${ }^{1}$ I would like to thank the two anonymous reviewers and editor who asked me to do relatively little in revising this article, but helped me to think a lot.

${ }^{2}$ http://www.issa.otago.ac.nz/about.html. Accessed 16th March 2012.
}

${ }^{3}$ None of these accounts make reference to the process of fragmentation which sociology was undergoing at this time, but it is surely also relevant that many new fields and subdisciplines emerged within sociology in the 1960s, in a manner akin to developments in physical education (Haney, 2008).

${ }^{4}$ ICSPE was founded in France in 1958. In 1982 it changed its name to the International Council of Sport Science and Physical Education. See www.icsspe.org.

${ }^{5}$ It should be noted that there are multiple spellings of this surname in the literature Nowikow, Novikov and Novikof. The particular spelling used is faithful to the particular source being reviewed.

${ }^{6}$ See http://www.issa.otago.ac.nz/about.html; http://www.nasss.org. Accessed 15 July 2010.

${ }^{7}$ While Lüschen cites 82 scholars he provides disciplinary backgrounds for 83 .

\section{References}

Abbott A (1988) The System of Professions: An Essay in the Division of Expert Labour. Chicago: University of Chicago Press. 
Anon (1976) International seminar for sociology of sport, October 2-5, 1975 in Heidelberg. International Review of Sociology of Sport 11(2): 153-160.

Atkinson M (2011) Physical Cultural Studies [Redux]. Sociology of Sport Journal 28(1): 135-44.

Beckford P (1796) Thoughts on Hare and Foxhunting. London.

Caillois R (1961) Man, Play and Games. Glencoe: Free Press.

Carrington B (2010) Sport, Race and Politics: The Sporting Black Diaspora. London: Sage.

Coakley J (1987) Sociology of sport in the United States. International Review for the Sociology of Sport 22(1): 63-79.

Coakley J and Dunning E (2000) General introduction. In: Coakley J and Dunning E (eds) Handbook of Sports Studies. London: Sage, xxi-xxxviii.

Coleman J (1961) The Adolescent Society. New York: Free Press.

Cozens FW and Stumpf FS (1953) Sports in American Life. Chicago: University of Chicago Press.

Daniels AS (1966/1969) The study of sport as an element of the culture. International Review of Sport Sociology, 1: 153-165. Reprinted in Loy J and Kenyon G (eds) Sport, Culture and Society: A Reader on the Sociology of Sport. New York: Macmillan, 13-22.

Dumazedier J (1964) The point of view of the social scientist. In Jokl E and Simon E (eds) International Research in Sport and Physical Education. Springfield, Il.: Thomas, 212-217.

Dumazedier J (1966) Toward a Society of Leisure. New York: Free Press.

Dunning E (1967) Notes on some conceptual and theoretical problems in the sociology of sport. International Review of Sport Sociology 2: 143-153.

Dunning E (2004) Sociology of sport in the balance: Critical reflections on some recent and more enduring trends. Sport in Society 7(1): 1-24. 
Edwards H (1969) The Revolt of the Black Athlete. New York: The Free Press.

Edwards H (1973) Sociology of Sport. Chicago Il.: Dorsey Press.

Egan P (1812) Boxiana. London: Sherwood.

Erbach G (1966/1969) The science of sport and sports sociology - questions related to development - problems of structure. International Review of Sport Sociology, 1: 5973. Reprinted in Loy J and Kenyon G (eds) Sport, Culture and Society: A Reader on the Sociology of Sport. New York: Macmillan, 23-36.

Freidson E (1970) Profession of Medicine: A Study of the Sociology of Applied Knowledge. New York: Dodd, Mead \& Co.

Goffman E (1961) Encounters. Bobbs-Merrill: Indianapolis.

Goudsblom J (1977) Sociology in the Balance: A Critical Essay. Oxford: Blackwell.

Gruneau R (1976) Sport as an area of sociological study: An introduction to major themes and perspectives. In Gruneau R and Albinson JG (eds) Canadian Sports: Sociological Perspectives. Reading, Mass.: Addison-Wesley, 8-43.

Grusky O (1963) Managerial succession and organizational effectiveness. American Journal of Sociology 69(1): 21-31.

Haney DP (2008) The Americanization of Social Science: Intellectuals and Public Responsibility in the Postwar United States. Philadelphia: Temple University Press.

Helanko R (1957) Sports and socialization. Acta Sociologica 2(4): 229-40.

Henry FM (1964) Physical education: An academic discipline. Journal of Health, Physical Education, and Recreation 35: 32-33.

Horkheimer M (1964) New patterns of social relations. In Jokl E and Simon E (eds) International Research in Sport and Physical Education. Springfield, Il.: Thomas, 173-185.

Huizinga J (1938/1949) Homo Ludens: A Study of the Play Element in Culture. London: Routledge and Kegan Paul. 
Ingham A and Loy J (1973) The social system of sport: A humanistic perspective. Quest 19: 3-23.

Ingham A and Donnelly P (1990) Whose knowledge counts? The production of knowledge and issues of application in the sociology of sport. Sociology of Sport Journal 7(1): 58-65.

Ingham A and Donnelly P (1997) A sociology of North American sociology of sport: Disunity in unity, 1965 to 1996. Sociology of Sport Journal 14(4): 362-418.

James CLR (1963) Beyond a Boundary. London: Hutchison.

Jokl E (1964) Medical Sociology and Cultural Anthropology of Sports and Physical Education. Springfield, Ill.: Thomas.

Jokl E and Simon E (eds) (1964) International Research in Sport and Physical Education. Springfield, Ill.: Thomas.

Kenyon GS and Loy J (1965/1969) Toward a sociology of sport. Journal of Health, Physical Education, and Recreation 36, 24-25, 68-69. Reprinted in Loy J and Kenyon G (eds) Sport, Culture and Society: A Reader on the Sociology of Sport. New York: Macmillan, 36-43.

Larson MS (1977) The Rise of Professionalism: A Sociological Analysis. Berkeley, CA: University of California Press.

Leemans EJ (1964) A sociological approach to sports. In Jokl E. and Simon E (eds) International Research in Sport and Physical Education. Springfield, Il.: Thomas, 152-159.

Loy J (1968) The nature of sport: a definitional effort. Quest 10: 1-15.

Loy J and Kenyon G (1969) The sociology of sport: An emerging field. In Loy J and Kenyon G (eds) Sport, Culture and Society: A Reader on the Sociology of Sport. New York: Macmillan, 1-8.

Loy J and Sage G (1997) Sociology of sport: Traditions, transitions, and transformations. Sociology of Sport Journal 14(4): 315-6. 
Lüschen G (1969) Sociology of sport in the United States. International Review of Sport Sociology 4: 189-190.

Lüschen G (1970) The Cross-Cultural Analysis of Sport and Games. Champaign, Il.: Stipes.

Lüschen G (1980) Sociology of sport: Development, present state, and prospects. Annual Review of Sociology 6: 315-47.

Lüschen G and Sage G (1981) Sport in sociological perspective. In Lüschen G and Sage G (eds) Handbook of Social Sciences of Sport. Champaign, Il.: Stipes Publishing, 3-24.

MacDonald KM (1995) The Sociology of the Professions. London: Sage.

Magnane G (1964) Sociologie du Sport. Paris: Gallimard.

McIntosh P (1960) Sport in Society. London: C.A. Watt.

McPherson B (1975) Past, present and future perspectives for research in sport sociology. International Review of Sport Sociology 10: 55-72.

McPherson BD, Curtis JE and Loy JW (1989) Defining sport. In McPherson BD, Curtis JE and Loy JW (eds) The Social Significance of Sport. Champaign, Il., Human Kinetics.

Mead GH (1934) Mind, Self and Society. Chicago: Chicago University Press.

Morton HW (1963) Soviet Sport. New York: Collier Books.

Natan A (1958) Sport and Society. London: Bowes and Bowes.

Parkin, F (1974) The Social Analysis of Class Structure. London: Tavistock Publications.

Riesman D and Denney R (1951) Football in America. American Quarterly 3: 309-19.

Risse H (1921) Soziologie des Sports. Berlin: Reher.

Roberts JM and Sutton-Smith B (1962) Child training and game involvement. Ethnology 1: 166-85.

Roberts JM, Arth MJ and Bush R (1959) Games in culture. American Anthropologist 61: 597-605. 
Sage G (1980) Study of social aspects of sport. In Sage G (ed.) Sport in American Society: Selected Readings. Reading Mass.: Addison Wesley, 1-15.

Sage G (1997) Physical education, sociology and sociology of sport: Points of intersection. Sociology of Sport Journal 14(4): 317-339.

Shearman M (1887) Football: Its History for Five Centuries. London: Longmans.

Shearman M (1889) Athletics and Football. London: Longmans.

Silk M and Andrews D (2011) Toward a physical cultural studies. Sociology of Sport Journal 28(1): 4-35.

Simmel G (1917) Grundfragen der Soziologie. Berlin: Göschen

Snyder E and Spreitzer E (1974/80) Sociology of sport: An overview. The Sociological Quarterly 15: 467-487. Reprinted in Sage G (ed.) Sport in American Society: Selected Readings. Reading, Mass.: Addison Wesley, 15-33.

Spencer H (1861) Education. New York: Williams and Northgate.

Steinitzer H (1910) Sport und Kultur. Munich.

Stone G (1955) American sports: Play and dis-play. Chicago Review 9(Fall): 83-100.

Sumner WG (1906) Folkways: A Study of the Sociological Importance of Usages, Manners, Customs, Mores and Morals. Boston: Ginn.

Sutton-Smith B, Roberts J and Kozelka R (1963) Game involvement in adults. Journal of Social Psychology 60: 15-30.

Thompson R (1964) Sport and Race. Oxford: Oxford University Press.

Veblen T (1899) The Theory of the Leisure Class: An Economic Study of Institutions. London: Macmillan.

Vlot NG (1964) Sociological analysis of sport in the Netherlands. In Jokl E and Simon E (eds) International Research in Sport and Physical Education. Springfield, Il.: Thomas, 198-211. 
Weber M (1904/1930) The Protestant Ethic and the Spirit of Capitalism. London: Allen and Unwin.

Weinberg S and Arond H (1952) The occupational culture of the boxer. American Journal of Sociology 62: 460-469.

Wohl A (1966) Conception and range of sport sociology. International Review for Sport Sociology 1(1): 5-18.

Wohl A (1969) Activity of the International Committee for Sociology of Sport in the years 1964-1968. International Review of Sport Sociology 4: 191-194.

Yiannakis A (1989) Toward an applied sociology of sport: The next generation. Sociology of Sport Journal 6(1): 1-16. 